\title{
Gliadin-based nanoparticles: Stabilization by post-production polysaccharide coating
}

\author{
Iris J. Joye ${ }^{\mathrm{a}, \mathrm{b},{ }^{*}, \text { Veronique A. Nelis }}{ }^{\mathrm{a}, \mathrm{b}}$, D. Julian McClements ${ }^{\mathrm{a}}$ \\ a Biopolymers and Colloids Research Laboratory, Department of Food Science, University of Massachusetts, Amherst, MA 01003, USA \\ ${ }^{\mathrm{b}}$ Department of Microbial and Molecular Systems, KU Leuven, 3001 Leuven, Belgium
}

\section{A R T I C L E I N F O}

Article history:

Received 18 February 2014

Accepted 27 May 2014

Available online $\mathrm{xxx}$

\section{Keywords:}

Gliadin

Pectin

Coating

Protein

Nanoparticle

Antisolvent precipitation

\begin{abstract}
A B S T R A C T
Introduction: There is great interest in converting gluten, a by-product from wheat starch isolation, into a value added functional food ingredient. Earlier, gliadin nanoparticles were produced using liquid antisolvent precipitation, but they did not prove to be very stable in conditions relevant to food products. Materials and methods: Gliadin nanoparticles were produced by antisolvent precipitation: a gliadin in ethanol solution was titrated into water. After production, the nanoparticles $(0.5 \mathrm{w} / \mathrm{v} \%$ protein) were coated with different polysaccharides: octenyl succinic anhydride (OSA) starch; low methoxyl pectin (LMP); or, high methoxyl pectin (HMP).

Results and discussion: At all concentrations used $(0.001-0.20 \mathrm{w} / \mathrm{v} \%)$, OSA-starch led to particle flocculation and precipitation, whereas both LMP and HMP were able to coat the particles without inducing flocculation at certain levels $(0.10 \mathrm{w} / \mathrm{v} \%)$. The mean particle size of pectin-coated particles was about double that of uncoated ones, and the charge reversed from positive (uncoated) to negative (coated) under mildly acidic conditions. The pectin coating was shown to improve the stability of the gliadin nanoparticles to environmental stresses, such as pH, ionic strength, and thermal treatment.

Conclusions: Coating gliadin nanoparticles with pectin may therefore be a useful means of forming stable functional ingredients for use in the food industry, e.g., as texture modifiers, lightening agents, or delivery systems.
\end{abstract}

๑) 2014 Elsevier Ltd. All rights reserved.

\section{Introduction}

The food industry is continually developing new and improved food and beverage products in response to consumer's desires for more convenient, healthier, tastier, and more economical products (Bigliardi \& Galati, 2013). Recently, there has been growing interest in the fortification of functional foods and beverages with various types of bioactive molecules. However, there are often challenges that need to be overcome before they can be successfully incorporated into commercial functional food and beverage products, e.g., low solubility, poor matrix compatibility, sensitivity to chemical degradation, and low bioavailability (Lamberts, Joye, Belien, \& Delcour, 2012; Matalanis, Decker, \& McClements, 2012;

Abbreviations: LAS, liquid antisolvent precipitation; GIT, gastrointestinal tract; HMP, high methoxyl pectin; LMP, low methoxyl pectin; NP, nanoparticle; OSAstarch, octenyl succinic anhydride starch; TEM, transmission electron microscopy.

* Corresponding author. Department of Microbial and Molecular Systems, KU Leuven, 3001 Leuven, Belgium. Tel.: +1 413545 7157; fax: +1 4135451262.

E-mail addresses: ijoye@foodsci.umass.edu, iris.joye@biw.kuleuven.be, joye@ biw.kuleuven.be (I.J. Joye).
SilvaCunha, Grossiord, Puisieux, \& Seiller, 1997). Different strategies have therefore been developed to encapsulate and protect bioactives during processing and storage, without compromising their release in the gastrointestinal tract (GIT) after ingestion (Onwulata, 2012). Proteins are excellent materials to build or stabilize encapsulation systems as they can form particles that are stable in food products but that degrade within the GIT due to the presence of peptidases (Duclairoir, Orecchioni, Depraetere, Osterstock, \& Nakache, 2003). Furthermore, their antioxidant properties may improve the stability of encapsulated bioactives to oxidation (Matalanis et al., 2012). Previous research (Duclairoir, Nakache, Marchais, \& Orecchioni, 1998; Ezpeleta et al., 1996; Joye, Nelis, \& McClements, submitted for publication) has already shown that protein nanoparticles (NPs) can be fabricated from gliadin, the main monomeric storage protein of wheat. Gliadin makes about half of gluten protein (Delcour et al., 2012), which is a reasonably cheap and readily available co-product of the wheat starch isolation industry. The formation of gliadin particles using antisolvent precipitation is based on the insolubility of gliadin in water. In principle, gliadin particles should therefore retain their 
integrity within aqueous-based food products. However, previous research (Joye et al., submitted for publication) has shown that protein nanoparticles are often unstable to dissolution or aggregation under conditions similar to those found in commercial food products. Electrostatic interactions play a major role in determining the structural integrity and aggregation of protein particles, which makes them highly sensitive to dissolution or aggregation when $\mathrm{pH}$ or ionic strength changes. On the other hand, polysaccharide particles are often much less sensitive to destabilization due to $\mathrm{pH}$ or ionic strength changes because they are mainly stabilized by steric hindrance (Dickinson, 2011). In this study, gliadin nanoparticles were produced using antisolvent precipitation, and then coated with a polysaccharide layer to improve their aggregation stability. The polysaccharides were used to examine the influence of their molecular characteristics on particle formation and stability: octenyl succinic anhydride (OSA) starch; high methoxyl pectin (HMP) and low methoxyl pectin (LMP). The influence of $\mathrm{pH}$, ionic strength, and temperature on the stability of the coated NPs was then assessed to establish their potential application in food and beverage products.

\section{Materials and methods}

\subsection{Chemicals}

All chemicals, reagents, and solvents were purchased from Fisher Scientific (Waltham, MA, USA) and were of analytical grade unless otherwise stated. Gluten was kindly provided by Cargill (Minneapolis, MN, USA). Low methoxyl [pectin LM35, degree of esterification 29\%, LMP] and high methoxyl [Genu ${ }^{\circledR}$ pectin (citrus), degree of esterification 61.4\%, HMP] pectin were obtained from Tic Gums (White Marsh, MD, USA) and CP Kelco (Atlanta, GA, USA), respectively. OSA-starch (Purity gum TM 2000) was obtained from Ingredion (Bridgewater, NJ, USA).

\subsection{Preparation of polysaccharide-coated gliadin nanoparticles}

Uncoated gliadin nanoparticles (NPs) were produced using the method described by Joye et al. (Joye et al., submitted for publication). In short, gliadin was extracted in a concentrated (70\%) ethanol solution $(0.03 \mathrm{~g} / \mathrm{mL})$ and then an aliquot $(2.00 \mathrm{~mL})$ was poured into water $(10.00 \mathrm{~mL})$ with continuous stirring at $440 \mathrm{rpm}$ at ambient temperature. After addition, the particle suspension was stirred for an additional 2 min before further manipulation or analysis.
Stock solutions of OSA-starch (2.00 w/v\%), HMP and LMP (each $1.50 \mathrm{w} / \mathrm{v} \%$ ) were prepared by dissolving these polysaccharides in water and stirring overnight. After dissolution, the $\mathrm{pH}$ of the OSAstarch and pectin solutions was adjusted to $\mathrm{pH} 5.0$ and 4.5, respectively. Freshly produced gliadin NP suspensions $(\sim 5 \mathrm{mg}$ protein $/ \mathrm{mL}$, i.e. $0.5 \mathrm{w} / \mathrm{v} \%$ ) were brought to the same $\mathrm{pH}$ as the polysaccharide solution (i.e. $\mathrm{pH} 5.0$ or 4.5$)$ using $\mathrm{HCl}(1.0 \mathrm{M})$. After $\mathrm{pH}$ adjustment, different concentrations of the polysaccharides were added to the gliadin NP suspensions. The concentration studied for OSA-starch ranged from 0.001 to $0.20 \mathrm{w} / \mathrm{v} \%$, while for pectin (LMP and HMP) it ranged from 0.01 to $0.20 \mathrm{w} / \mathrm{v} \%$. The production process is shown schematically in Fig. 1.

\subsection{Particle characterization}

\subsubsection{Particle size and charge}

The particle size distribution of the protein particles was determined using dynamic light scattering (Zetasizer Nano ZS series, Malvern Instruments, Worcestershire, UK). The $\zeta$-potential was determined by particle electrophoresis (Zetasizer Nano ZS series, Malvern Instruments, Worcestershire, UK). All measurements were carried out at $25{ }^{\circ} \mathrm{C}$.

\subsubsection{Particle microstructure}

Particle morphology was studied in more detail using transmission electron microscopy (TEM). Prior to analysis, samples were diluted 20-fold in an aqueous phase similar to that of the original sample. 1 day-old diluted samples were directly deposited onto inhouse made grids without prior purification. Excess sample was gently removed by absorption using filter paper and negatively stained using 2.0\% aqueous uranyl acetate. After incubating for $20 \mathrm{~s}$, the negative staining solution was gently removed by absorption using filter paper and the negatively stained samples were allowed to air-dry. The dry samples were observed under high vacuum conditions within the TEM (100 kV, Tecnai 12, FEI, Hillsboro, Oregon, USA).

\subsubsection{Particle stability}

2.3.3.1. Stability to thermal processing. Freshly prepared particle dispersions were brought to $\mathrm{pH}$ 5.5, distributed over different glass test tubes, and then incubated in water baths set at different temperatures $\left(30-90{ }^{\circ} \mathrm{C}\right.$ ) for $30 \mathrm{~min}$. The samples were subsequently allowed to cool down to room temperature and the particle size distribution was analyzed as described above $24 \mathrm{~h}$ after the heat treatment.

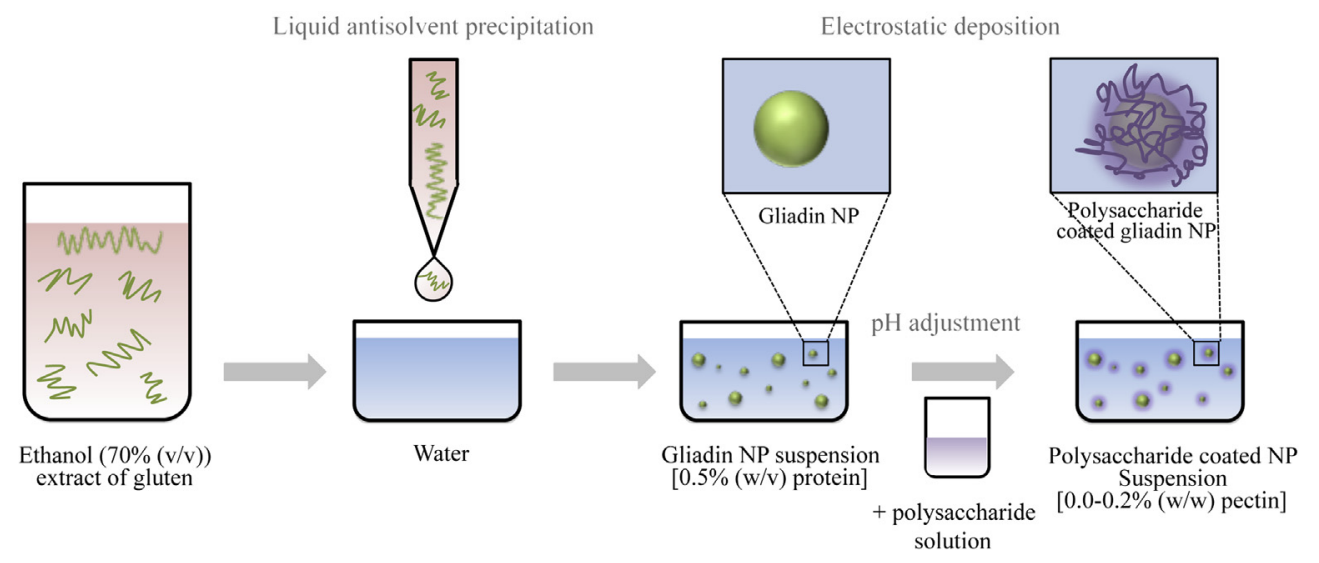

Fig. 1. Schematic representation of the production and coating process of gliadin nanoparticles (NPs). 
2.3.3.2. Stability to isothermal storage. Freshly prepared particle dispersions were brought to $\mathrm{pH} 5.5$, distributed over different glass test tubes, and then incubated in temperature controlled chambers set at different temperatures $\left(4,23,37\right.$ and $\left.55^{\circ} \mathrm{C}\right)$ for up to 3 weeks.

2.3.3.3. Stability to different $\mathrm{pH}$ conditions. Freshly prepared particle dispersions were distributed over different glass test tubes and then their $\mathrm{pH}$ was adjusted by adding $\mathrm{NaOH}$ or $\mathrm{HCl}$ to obtain values ranging from $\mathrm{pH} 3.0$ to 7.0. The particle size distribution of these samples was determined $24 \mathrm{~h}$ after adjustment of the $\mathrm{pH}$.

2.3.3.4. Stability to different ionic strength conditions. Freshly prepared particle dispersions were brought to $\mathrm{pH} 5.5$ and distributed over different glass test tubes. The ionic strength of the particle dispersions was altered by adding a highly concentrated $\mathrm{NaCl}$ solution $(6.0 \mathrm{M})$ to obtain samples containing $0-500 \mathrm{mM} \mathrm{NaCl}$. The particle size distribution of these samples was determined $24 \mathrm{~h}$ after adjustment of the ionic strength.

\subsection{Statistical analysis}

All data are reported as mean values with standard deviations. Tukey's tests ( $p$ value $<0.05$ ) were performed using XLStat Software (Addinsoft, Brooklyn, NY, USA).

\section{Results and discussion}

\subsection{Uncoated particles}

The production of uncoated gliadin particles has been described in earlier reports (Duclairoir et al., 1998; Ezpeleta et al., 1996; Joye et al., submitted for publication). These particles had diameters ranging from 150 to $900 \mathrm{~nm}$ depending on system composition and preparation method. The particles previously produced by antisolvent preparation in our laboratory had diameters well below $200 \mathrm{~nm}$ (Joye et al., submitted for publication), with the mean diameter depending on the production parameters used. The uncoated gliadin particles

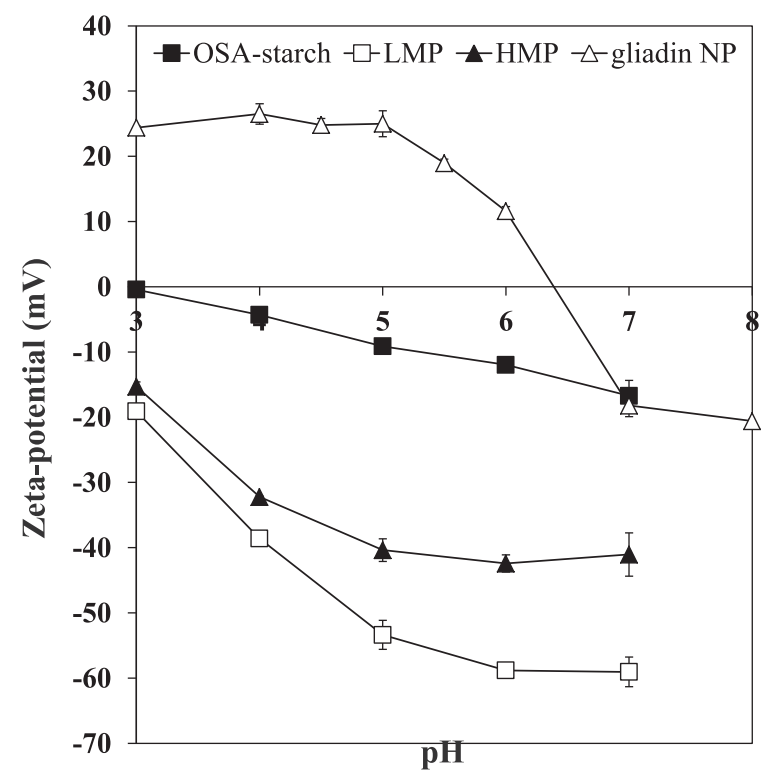

Fig. 2. Influence of $\mathrm{pH}$ on the $\zeta$-potential of the gliadin nanoparticles, octenyl succinic anhydride (OSA) starch and low (LMP) and high (HMP) methoxyl pectin. produced in the current study had a mean diameter of about $200 \mathrm{~nm}$ and a $\zeta$-potential of $+20 \mathrm{mV}$ at the preparation $\mathrm{pH}$ of 5.5. The $\zeta$-potential of the gliadin particles changed from positive to negative as the $\mathrm{pH}$ was increased from 2.0 to 9.0 , with a point of

(a)

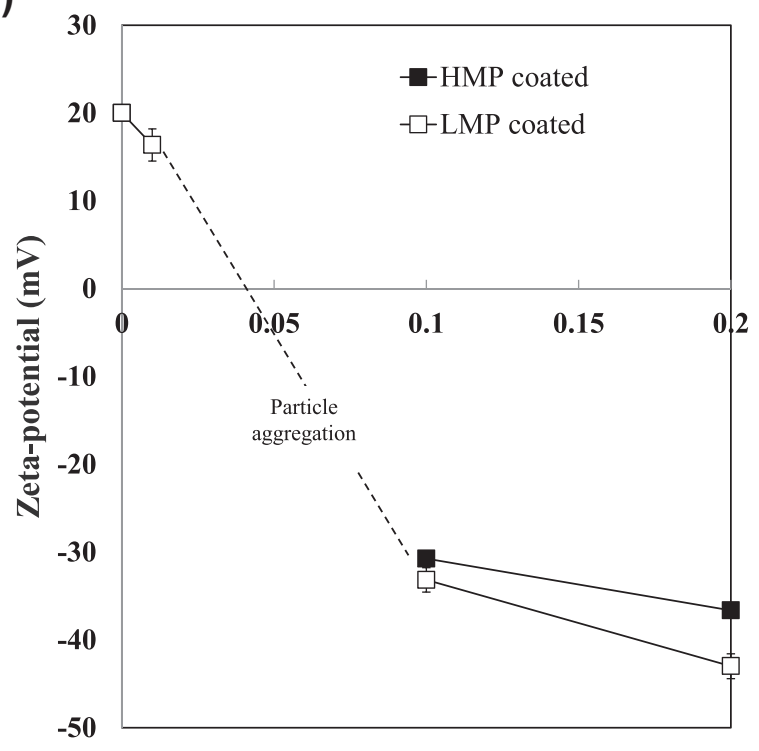

(b)
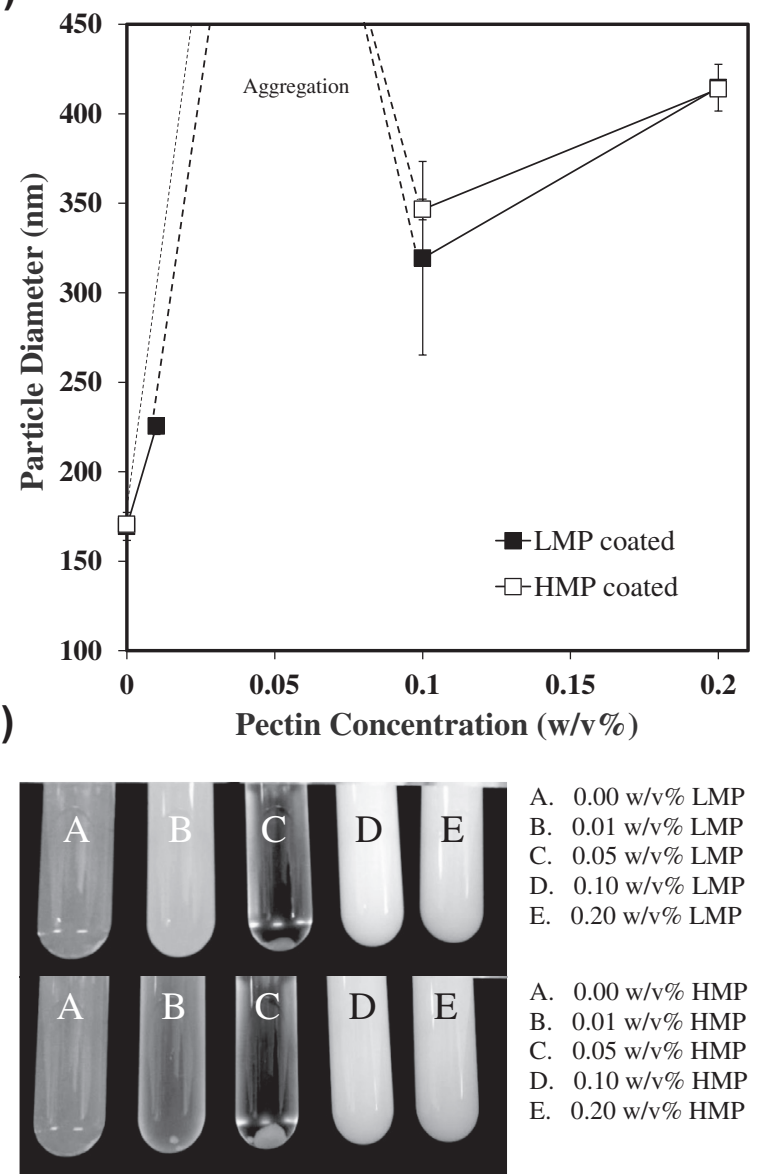

A. $0.00 \mathrm{w} / \mathrm{v} \% \mathrm{LMP}$ B. $0.01 \mathrm{w} / \mathrm{v} \% \mathrm{LMP}$ C. $0.05 \mathrm{w} / \mathrm{v} \% \mathrm{LMP}$ D. $0.10 \mathrm{w} / \mathrm{v} \% \mathrm{LMP}$ E. $0.20 \mathrm{w} / \mathrm{v} \% \mathrm{LMP}$

A. $0.00 \mathrm{w} / \mathrm{v} \% \mathrm{HMP}$ B. $0.01 \mathrm{w} / \mathrm{v} \% \mathrm{HMP}$ C. $0.05 \mathrm{w} / \mathrm{v} \%$ HMP D. $0.10 \mathrm{w} / \mathrm{v} \%$ HMP E. $0.20 \mathrm{w} / \mathrm{v} \% \mathrm{HMP}$

Fig. 3. Effect of pectin concentration on particle properties. (a) $\zeta$-potential of the particles in function of pectin concentration. (b) Diameter of the particles in function of pectin concentration. (c) Photographs show the effect of increasing pectin concentration on visual appearance and macroscale stability of the particle suspensions. 
zero charge around pH 6.5 (Fig. 2). These results are in agreement with our previous study on uncoated gliadin nanoparticles (Joye et al., submitted for publication). These particles were somewhat larger than the ones we produced previously, which can be attributed to the fact that we used different mixing conditions.

\subsection{Coating with polysaccharides}

In our previous study, we showed that uncoated particles had limited stability to $\mathrm{pH}$, ionic strength, and temperature conditions generally encountered during food processing, which would limit their potential commercial application (Joye et al., submitted for publication). In this study, we therefore examined the influence of coating the protein NPs with a polysaccharide layer to modify their surface characteristics and thereby improve their stability. Coating of the NPs was carried out by electrostatic deposition of the charged polysaccharide onto the oppositely charged protein particle. The adsorption of the polysaccharide onto the particle surface needs to be optimized so that flocculation defects are avoided. Addition of too little polysaccharide can lead to bridging flocculation, whereas addition of too much polysaccharide can lead to depletion flocculation.

(a)

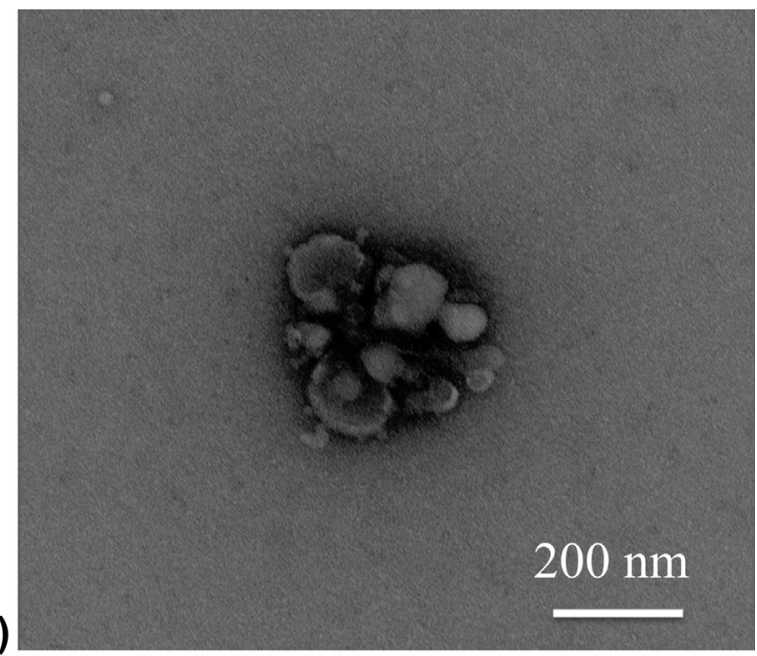

(b)

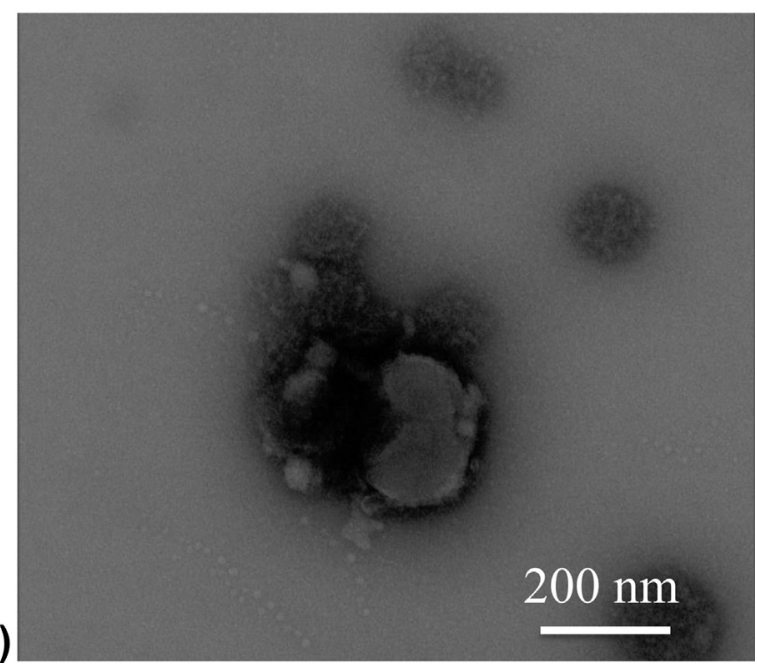

Fig. 4. Transmission electron microscope images of uncoated (a) and high methoxyl pectin coated protein particles ( $0.10 \mathrm{w} / \mathrm{v} \% \mathrm{HMP})(\mathrm{b})$.

\subsubsection{OSA-starch}

OSA-starch is modified starch to which octenyl succinic anhydride is esterified. The modified starch therefore becomes hydrophobic due to the introduction of an octenyl group and slightly anionic due to the introduction of a carboxylic acid. The resulting molecule displays amphiphilic properties and can function as an emulsifier or encapsulating agent. Due to its high molar mass and branched structure, it has been used before to stabilize food colloids by steric stabilization (Nilsson \& Bergenstahl, 2006). OSAstarch was negatively charged from $\mathrm{pH} 3.0$ to 7.0 with the magnitude of the charge decreasing with decreasing $\mathrm{pH}$ (Fig. 2). A pH of 5.0 was selected to carry out the coating step based on the $\zeta$-potential versus $\mathrm{pH}$ profiles of the gliadin NPs and OSA-starch (Fig. 2): at this $\mathrm{pH}$ the protein nanoparticles were positively charged, but the starch molecules were negatively charged. Varying amounts of OSA-starch were added to a suspension containing $0.5 \mathrm{w} / \mathrm{v} \%$ gliadin nanoparticles. Our experiments showed that the addition of OSAstarch at all levels studied $(0.001-0.20 \mathrm{w} / \mathrm{v} \%)$ led to extensive flocculation of the gliadin nanoparticles as evidenced by the formation of visible aggregates that rapidly sedimented (data not shown). For this reason, we did not use the OSA-starch in the subsequent experiments.

\subsubsection{Pectin}

Pectin was used as an example of an anionic polysaccharide that is already widely utilized as a functional ingredient in the food industry. Two types of pectin were used with different degrees of esterification so as to have molecules with different electrical characteristics, i.e. LMP (high charge density) and HMP (low charge density). These differences in electrical characteristics were reflected in the $\zeta$-potential versus $\mathrm{pH}$ profiles of the LMP and HMP molecules (Fig. 2): LMP was more negatively charged than HMP at all $\mathrm{pH}$ levels. For both types of pectin, the negative charge became less negative with decreasing $\mathrm{pH}$, which can be attributed to protonation of the carboxyl groups on the pectin molecules around their $\mathrm{pK}_{\mathrm{a}}$ values $(\approx 3.5)$. A pH of 4.5 was selected to carry out the electrostatic coating process since the protein nanoparticles were

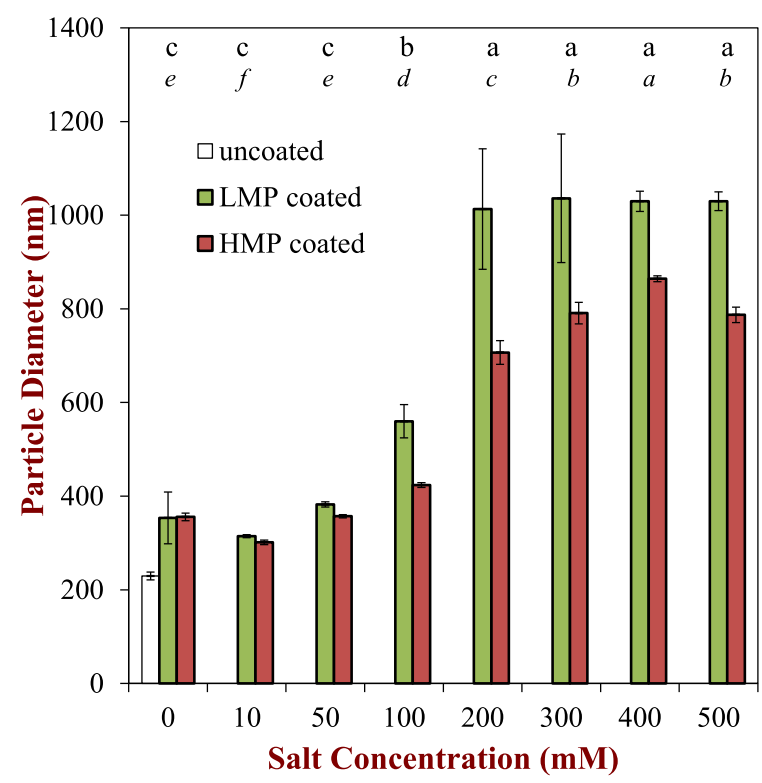

Fig. 5. Particle stability in different salt concentrations. Particle diameter was recorded $24 \mathrm{~h}$ after addition of $\mathrm{NaCl}$ to the particle suspensions, i.e. uncoated and coated with low methoxyl pectin (LMP, $0.10 \mathrm{w} / \mathrm{v} \%$ ) and high methoxyl pectin (HMP, $0.10 \mathrm{w} / \mathrm{v} \%$ ) at pH 5.5. a-c; and $a-f$ represent Tukey groups with $p<0.05$ for comparison of the evolution of the particle diameters of LMP and HMP coated gliadin particles, respectively, in function of $\mathrm{NaCl}$ concentration. 
highly positive, while the polysaccharides were highly negatively charged at this pH (Fig. 2).

Varying amounts of pectin $(0.01-0.2 \mathrm{w} / \mathrm{v} \%)$ were added to a suspension of gliadin nanoparticles $(0.5 \mathrm{w} / \mathrm{v} \%)$ to determine the optimum coating level required. The $\zeta$-potential measurements indicated that the particle charge went from positive (uncoated) to negative (coated) as the pectin concentration was increased (Fig. 3a), which supports the hypothesis that pectin adsorbed to the gliadin particle surfaces. Reliable measurements could not be made at intermediate pectin concentrations (i.e. 0.01 and $0.05 \mathrm{w} / \mathrm{v} \%$ ) due to extensive particle aggregation, which can be attributed to bridging effects, i.e., adsorption of pectin to more than one protein particle. The particle charge did not change appreciably at pectin
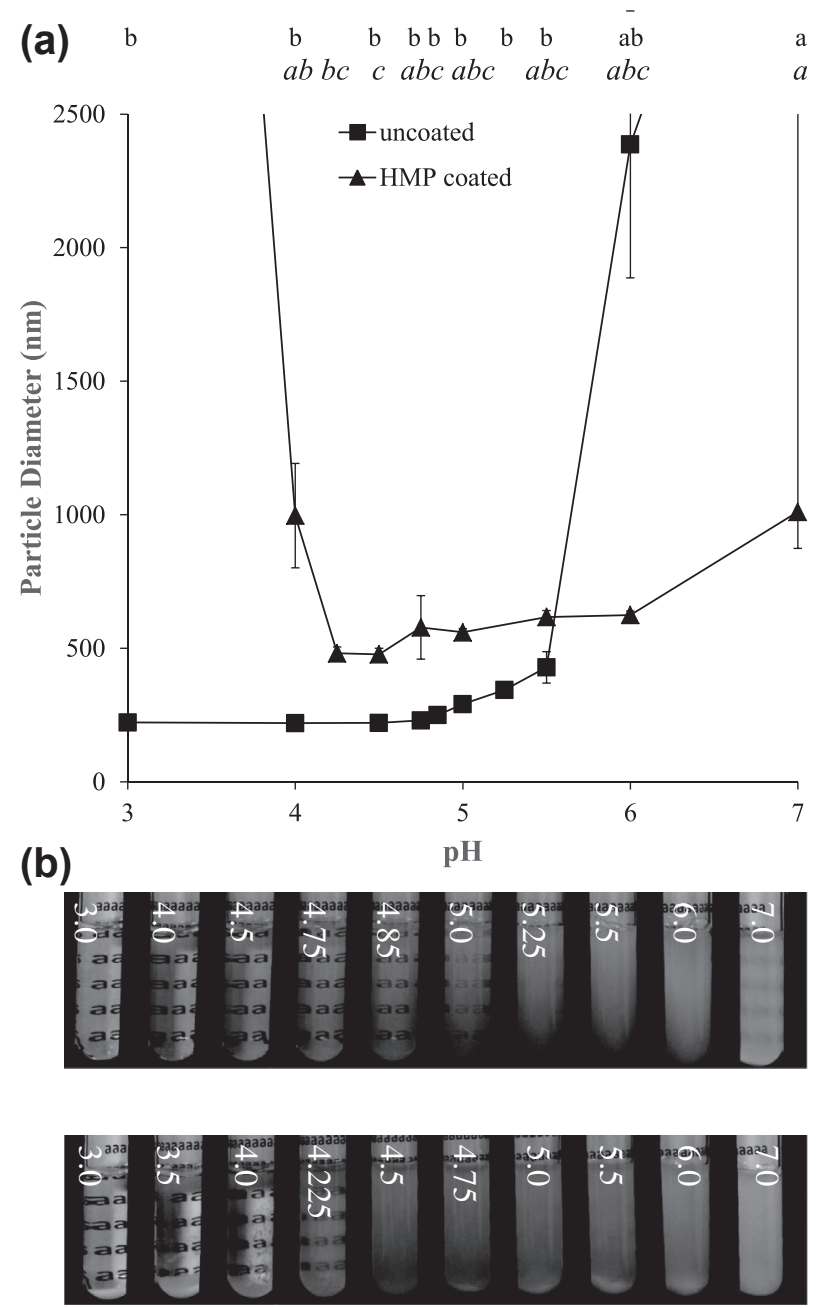

LMP coated

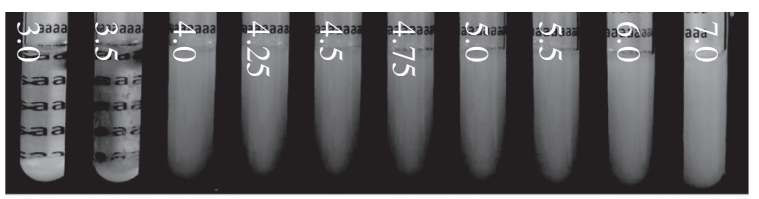

HMP coated

Fig. 6. Particle stability in different $\mathrm{pH}$ conditions. (a) The effect of $\mathrm{pH}$ on particle diameter of uncoated and coated with high methoxyl pectin (HMP, $0.10 \mathrm{w} / \mathrm{v} \%$ ) gliadin particles. The reported values were recorded $24 \mathrm{~h}$ after $\mathrm{pH}$ adjustment. a-b and $a-c$ represent Tukey groups with $p<0.05$ for uncoated and HMP coated particles respectively. (b) The effect of $\mathrm{pH}$ on macroscale stability of uncoated, low methoxyl pectin (LMP) and HMP coated gliadin particles. concentrations exceeding $0.10 \mathrm{w} / \mathrm{v} \%$, which suggested that they were already saturated with pectin. As expected, LMP-coated gliadin NPs had a higher negative charge than HMP-coated ones, which can be attributed to differences in the anionic charge density of the two pectins.

The measured particle size roughly doubled after coating of the gliadin NPs and the turbidity of the suspension visibly increased (Fig. $3 \mathrm{~b}$ and c). At $0.05 \mathrm{w} / \mathrm{v} \%$ pectin, extensive particle aggregation

(a)

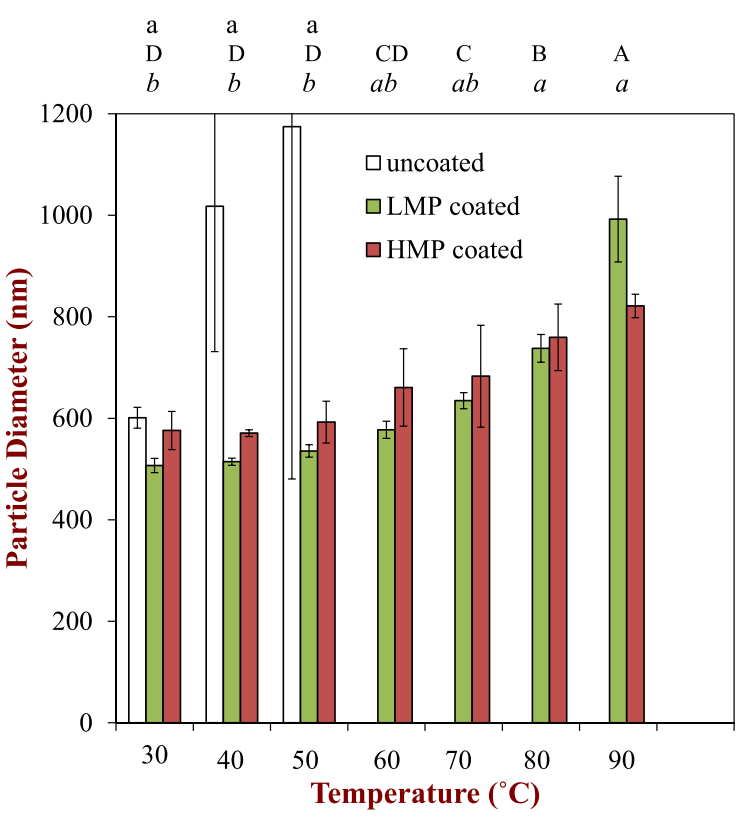

(b)
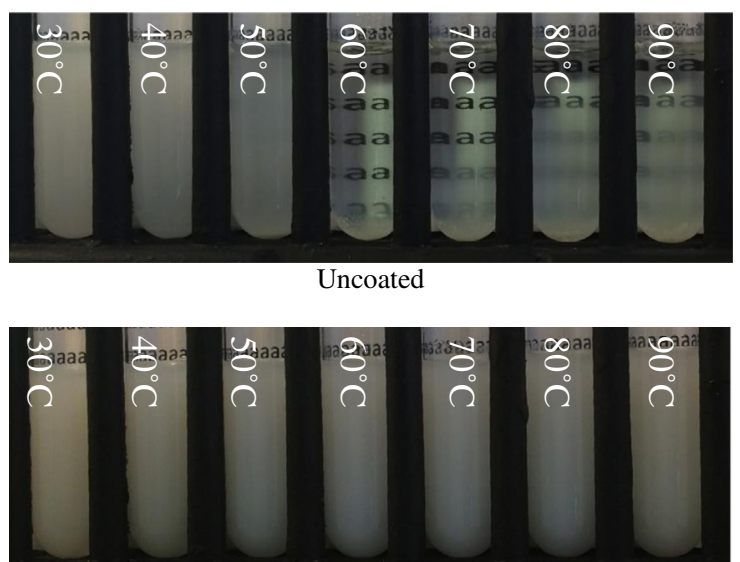

LMP coated

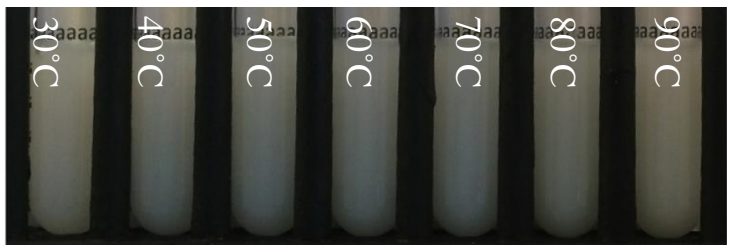

HMP coated

Fig. 7. Particle stability to heat processing. (a) The effect of heat processing on particle diameter. Particle diameter was recorded $24 \mathrm{~h}$ after the heat treatment of the different particle suspensions, i.e. uncoated particle suspension and low methoxyl pectin (LMP) and high methoxyl pectin (HMP) coated particle suspension (both $0.10 \mathrm{w} / \mathrm{v} \%$ pectin) at $\mathrm{pH}$ 5.5. a; A-D and $a-b$ represent Tukey groups with $p<0.05$ for comparison of the evolution of the particle diameters per suspension type (i.e. uncoated, LMP and HMP) in function of temperature during heat processing. (b) The effect of heat processing on macroscale stability of uncoated, LMP and HMP coated gliadin particles. 
and sedimentation was observed (Fig. 3c), and no reliable particle size measurements could be performed. This phenomenon is probably caused by charge neutralization and bridging flocculation effects due to pection addition. The adsorption of pectin molecules to the particle surfaces reduces their positive charge, thereby decreasing the electrostatic repulsion between particles. In addition, if the particles are not fully coated by polysaccharide then a pectin molecule may adsorb onto the surfaces of more than one particle leading to bridging. Information about the microstructure of the particles was obtained using transmission electron microscopy. The uncoated gliadin particles appeared to be clumped together into small globular structures (Fig. 4). The suspension containing the coated gliadin particles appeared to contain some clumps and some individual protein particles. This suggests that the pectin may have been able to disrupt some of the clumps in the original sample, and that it may have adsorbed around clumps of protein particles as well as around individual protein particles. The increase in particle size observed in the dynamic light scattering experiments upon formation of the clumps (Fig. 3b) may have been due to the presence of the adsorbed pectin coating around the particles or clumps.

For both types of pectin, $0.10 \mathrm{w} / \mathrm{v} \%$ polysaccharide was selected as the most suitable coating concentration for further experiments since this led to particles with a high negative charge and relatively small size (Fig. 3).

\subsection{Stability of coated gliadin particles}

\subsubsection{Salt stability}

Previous studies have shown that dispersions of uncoated gliadin particles are destabilized and precipitate in even low levels of salt, i.e. $10 \mathrm{mM} \mathrm{NaCl}$ (Joye et al., submitted for publication). In the current study, we found that the coated particles were also sensitive to salt, but that they had better stabilities than the uncoated particles. The mean particle diameters of the coated particles did not change appreciably from 0 to $50 \mathrm{mM} \mathrm{NaCl}$, but then they increased appreciably at higher salt levels (Fig. 5). Indeed, the particle size increased roughly 2- or 3-fold upon addition of $200 \mathrm{mM} \mathrm{NaCl}$ for HMP and LMP coated particles, respectively. Higher salt concentrations did not further affect the particle diameter. Coating with HMP or LMP $(0.10 \mathrm{w} / \mathrm{v} \%)$ also significantly improved the stability of the particles to gravitational separation in salt solutions containing up to $500 \mathrm{mM}$ $\mathrm{NaCl}$. This lets us speculate that the stability imposed by pectin coating is not exclusively caused by electrostatic repulsion, but steric hindrance can also be a stabilizing factor.

\subsection{2. $p H$ stability}

The mean diameter of the uncoated gliadin NPs did not change appreciably from pH 3.0 to 5.0 (Fig. 6), which can be attributed to the large electrostatic repulsion between them associated with their high positive charge (Fig. 2). At pH 5.0 and above, the particle diameter increased with increasing $\mathrm{pH}$, which can be attributed to the reduction in electrostatic repulsion between the particles at elevated $\mathrm{pH}$. At $\mathrm{pH}$ values above 5.5, a sharp increase in the particle size was observed and a precipitate formed. LMP coated particles were immediately destabilized upon adjustment of the $\mathrm{pH}$ (data not shown). Conversely, HMP-coated particles had fairly stable particle diameters from $\mathrm{pH} 4.25$ to $\mathrm{pH}$ 7.0. At $\mathrm{pH} 4.5$, the $\zeta$-potential of the coated particles was around $-30 \mathrm{mV}$, which should be large enough to ensure good stability through electrostatic repulsion (Jahanshahi \& Babaei, 2008). The extensive aggregation observed in the coated particles at lower pH values (Fig. 6b) may be attributed to a reduction in particle charge due to protonation of the carboxyl groups on the pectin molecules around their $\mathrm{pK}_{\mathrm{a}}$ values (Hou, Chang, \& Jiang, 1999). At $\mathrm{pH}$ values above $\mathrm{pH} 7.0$, no reliable measurements of the particle size were obtained as very high polydispersity indices were found. This may have been because the pectin molecules desorbed from the gliadin nanoparticle surfaces

\section{Table 1}

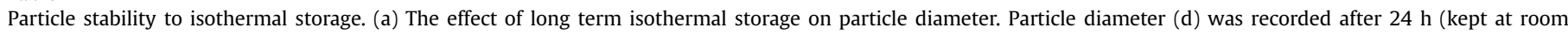

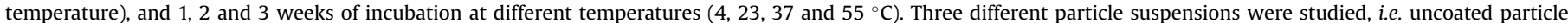

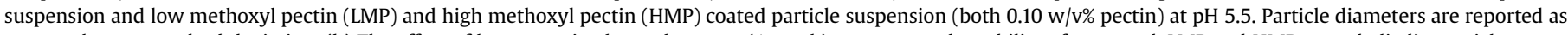
mean values \pm standard deviation. (b) The effect of long term isothermal storage ( 1 week) on macroscale stability of uncoated, LMP and HMP coated gliadin particles.

(a)

\begin{tabular}{|c|c|c|c|c|c|c|c|c|c|c|c|c|}
\hline \multirow[t]{2}{*}{$\mathrm{T}\left({ }^{\circ} \mathrm{C}\right)$} & \multicolumn{4}{|c|}{ Uncoated particles } & \multicolumn{4}{|c|}{ LMP coated particles } & \multicolumn{4}{|c|}{ HMP coated particles } \\
\hline & $\begin{array}{c}\text { Freshly } \\
\text { made }\end{array}$ & $\begin{array}{c}\mathrm{d}(1 \text { week }) \\
(\mathrm{nm})\end{array}$ & $\begin{array}{c}\mathrm{d}(2 \text { weeks }) \\
(\mathrm{nm})\end{array}$ & $\begin{array}{c}\mathrm{d}(3 \text { weeks }) \\
(\mathrm{nm})\end{array}$ & $\begin{array}{c}\text { Freshly } \\
\text { made }\end{array}$ & $\begin{array}{c}\mathrm{d}(1 \text { week }) \\
(\mathrm{nm})\end{array}$ & $\begin{array}{c}\mathrm{d}(2 \text { weeks }) \\
(\mathrm{nm})\end{array}$ & $\begin{array}{c}\mathrm{d}(3 \text { weeks }) \\
(\mathrm{nm})\end{array}$ & $\begin{array}{l}\text { Freshly } \\
\text { made }\end{array}$ & $\begin{array}{c}\mathrm{d}(1 \text { week }) \\
(\mathrm{nm})\end{array}$ & $\begin{array}{c}\mathrm{d}(2 \text { weeks }) \\
(\mathrm{nm})\end{array}$ & $\begin{array}{c}\mathrm{d}(3 \text { weeks }) \\
(\mathrm{nm})\end{array}$ \\
\hline 4 & \multirow{4}{*}{$\begin{array}{l}\text { oे } \\
\text { मे } \\
\text { ते }\end{array}$} & $282 \pm 8$ & $331 \pm 14$ & $320 \pm 17$ & \multirow{4}{*}{ 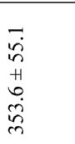 } & $484 \pm 18$ & $498 \pm 11$ & $531 \pm 37$ & \multirow{4}{*}{$\begin{array}{l}\infty \\
H \\
\stackrel{H}{0} \\
\infty \\
0\end{array}$} & $540 \pm 67$ & $553 \pm 20$ & $553.6 \pm 1.7$ \\
\hline 20 & & $347 \pm 18$ & $390 \pm 47$ & $433 \pm 60$ & & $485 \pm 6$ & $500 \pm 15$ & $496 \pm 6$ & & $555 \pm 11$ & $555 \pm 21$ & $561 \pm 23$ \\
\hline 37 & & $3536 \pm 628$ & $*$ & $*$ & & $510 \pm 2$ & $542 \pm 29$ & $521 \pm 28$ & & $591 \pm 38$ & $580 \pm 13$ & $545 \pm 23$ \\
\hline 55 & & $5426 \pm 1794$ & * & * & & $582 \pm 72$ & $558 \pm 58$ & $604 \pm 157$ & & $575 \pm 14$ & $556 \pm 24$ & $541 \pm 31$ \\
\hline
\end{tabular}

* sample precipitated

(b)

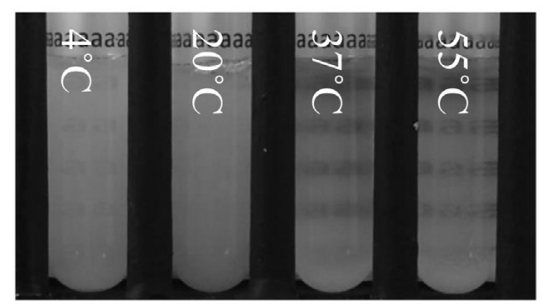

Uncoated

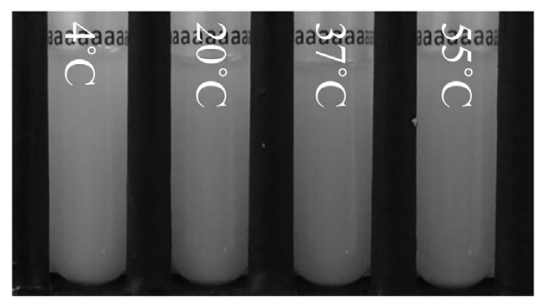

LMP coated

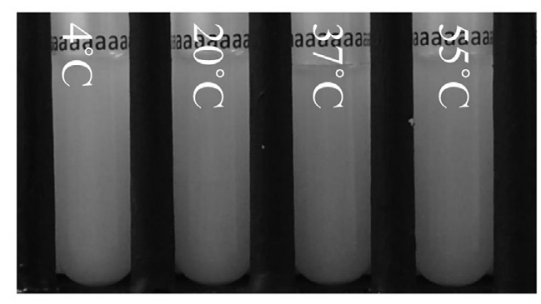

HMP coated 
due to a reduction in electrostatic attraction and increase in electrostatic repulsion at high $\mathrm{pH}$ values (both gliadin and pectin are negatively charged). Nevertheless, the particle suspensions still appeared visibly stable at the higher $\mathrm{pH}$ levels, which suggested that aggregation did not occur (Fig. 6b). Coating of the NPs, hence, did not substantially improve the pH stability of the NPs in the low $\mathrm{pH}$ range $(\mathrm{pH}<4.25)$, but produced particles with a higher stability at $\mathrm{pH}$ values above 5.75. This is important information for designing gliadin nanoparticles for different commercial products.

\subsubsection{Thermal stability}

Finally, we examined the influence of thermal treatments on the stability of uncoated and coated gliadin nanoparticles. Particle suspensions of uncoated NPs at pH 5.5 were quickly destabilized by short term thermal treatments once the temperature exceeded $50{ }^{\circ} \mathrm{C}$ (Fig. 7). Coating the gliadin nanoparticles with pectin clearly improved their thermal stability, although there was still some increase in particle size with increasing incubation temperature (Fig. 7a). Presumably, the polysaccharide coatings increased the steric repulsion between the particles, which inhibited particle aggregation induced by heating. The same stabilizing effect of pectin coating was observed for particle suspensions stored for longer times ( 3 weeks) at temperatures varying between 4 and $55{ }^{\circ} \mathrm{C}$ (Table 1). At higher temperatures, the particle collision frequency in suspensions generally increases which promotes the formation of larger particles through particle aggregation. Pectin most probably provides improved stability by generating both electrostatic and steric repulsion between the particles. To fully explore the nature of the stabilization mechanism, more in-depth knowledge on the structure of the polysaccharides is needed.

\section{Conclusions}

This study has shown that gliadin nanoparticles can be stabilized against aggregation under certain conditions by coating them with anionic polysaccharides (pectin). The stability of the gliadin nanoparticles to changes in ionic strength and temperature were significantly improved by coating them with pectin. The $\mathrm{pH}$ range in which the gliadin particles were stable to aggregation shifted to higher $\mathrm{pH}$ values upon coating. This study shows that the stability of gliadin nanoparticles can be improved using electrostatic coating strategies. Additional hardening of the protein and/or polysaccharide structures may infer additional stability, but further research is required to establish this. Furthermore, additional research is also necessary to evaluate the possibility of loading different kinds of bioactives into these protein nanoparticles and on establishing their ability to protect and release these bioactives in foods and the human body.

\section{Acknowledgements}

The authors thank the United States Department of Agriculture, CREES, NRI and AFRI Grants, and Massachusetts Department of Agricultural Resources for financial support of this work. Iris Joye gratefully acknowledges financial support from the 'Fonds voor Wetenschappelijk Onderzoek - Vlaanderen' (FWO, Brussels, Belgium) and from the European Commission 7th Framework Program (FP7-People-2011-IOF-300408).

\section{References}

Bigliardi, B., \& Galati, F. (2013). Innovation trends in the food industry: the case of functional foods. Trends in Food Science and Technology, 31, 118-129.

Delcour, J. A., Joye, I. J., Pareyt, B., Wilderjans, E., Brijs, K., \& Lagrain, B. (2012). Wheat gluten functionality as a quality determinant in cereal-based food products. Annual Reviews in Food Science and Technology, 3, 469-492.

Dickinson, E. (2011). Double emulsions stabilized by food biopolymers. Food Biophysics, 6, 1-11.

Duclairoir, C., Nakache, E., Marchais, H., \& Orecchioni, A. M. (1998). Formation of gliadin nanoparticles: influence of the solubility parameter of the protein solvent. Colloid and Polymer Science, 276, 321-327.

Duclairoir, C., Orecchioni, A. M., Depraetere, P., Osterstock, F., \& Nakache, E. (2003). Evaluation of gliadins nanoparticles as drug delivery systems: a study of three different drugs. International Journal of Pharmaceutics, 253, 133-144.

Ezpeleta, I., Irache, J. M., Stainmesse, S., Chabenat, C., Gueguen, J., Popineau, Y., et al. (1996). Gliadin nanoparticles for the controlled release of all-trans-retinoic acid. International Journal of Pharmaceutics, 131, 191-200.

Hou, W. C., Chang, W. H., \& Jiang, C. M. (1999). Qualitative distinction of carboxyl group distributions in pectins with ruthenium red. Botanical Bulletin of Academia Sinica, 6, 115-119.

Jahanshahi, M., \& Babaei, Z. (2008). Protein nanoparticle: a unique system as drug delivery vehicles. African Journal of Biotechnology, 7, 4926-4934.

Joye, I. J., Nelis, V. A., \& McClements, D. J. (2014). Gliadin-based nanoparticles: fabrication and stability of food-grade colloidal delivery systems (submitted for publication).

Lamberts, L., Joye, I. J., Belien, T., \& Delcour, J. A. (2012). Dynamics of gammaaminobutyric acid in wheat flour bread making. Food Chemistry, 130(4), 896-901.

Matalanis, A., Decker, E. A., \& McClements, D. J. (2012). Inhibition of lipid oxidation by encapsulation of emulsion droplets within hydrogel microspheres. Food Chemistry, 132(2), 766-772.

Nilsson, L., \& Bergenstahl, B. (2006). Adsorption of hydrophobically modified starch at oil/water interfaces during emulsification. Langmuir, 22(21), 8770-8776.

Onwulata, C. I. (2012). Encapsulation of new active ingredients. Annual Reviews in Food Science and Technology, 3, 183-202.

SilvaCunha, A., Grossiord, J. L., Puisieux, F., \& Seiller, M. (1997). W/O/W multiple emulsions of insulin containing a protease inhibitor and an absorption enhancer: preparation, characterization and determination of stability towards proteases in vitro. International Journal of Pharmaceutics, 158(1), 79-89. 